\title{
A INFLUÊNCIA DA VEGETAÇÃO NO CONFORTO TÉRMICO PARA A CONDIÇÃO MICROCLIMÁTICA DE VITÓRIA (ES)
}

\author{
Brenda Alves Silva ${ }^{1}$
}

Tatiana Camello Xavier ${ }^{2}$

Cristina Engel de Alvarez ${ }^{3}$

\section{RESUMO}

O crescimento urbano acelerado e a ocupação desordenada do solo podem influenciar negativamente no microclima. Dessa forma a vegetação é um importante instrumento no auxílio para o provimento de um ambiente termicamente mais agradável. O objetivo deste trabalho foi avaliar o impacto de alguns diferentes tipos de distribuição de vegetação inseridos no meio urbano em relação ao conforto térmico. Foi considerado um trecho urbano, tipologicamente similar na cidade de Vitória (ES), localizado nos bairros Jardim da Penha e Mata da Praia. Para as medições, foram selecionados quatro pontos de amostragem distribuídos retilineamente a partir do Parque Pedra da Cebola. Foram medidas as variáveis climáticas temperatura, umidade e velocidade do vento, realizadas simultaneamente durante três horas ininterruptas no verão, considerando horários de maior incidência solar do dia. Os dados encontrados nas medições permitiram constatar a influência da vegetação como um forte condicionante para o conforto térmico. Verificou-se que a influência térmica da vegetação concentrada no Parque ocorre apenas no entorno imediato no que diz respeito à temperatura, no entanto, em relação à umidade, o raio de interferência é maior. A vegetação distribuída apresenta resultados mais satisfatórios em relação à temperatura, quando comparado à sua disposição concentrada, concluindo-se que embora os parques urbanos exerçam influência no conforto do entorno imediato, a distribuição da vegetação na malha urbana tende a trazer melhores resultados.

PALAVRAS-CHAVE: Vegetação urbana. Clima urbano. Conforto térmico.

\footnotetext{
${ }^{1}$ Graduanda em Geografia, Bolsista de Iniciação Científica, Universidade Federal do Espírito Santo, brendaasilva@hotmail.com.

${ }^{2}$ Arquiteta e Urbanista, Mestranda em Arquitetura e Urbanismo, Universidade Federal do Espírito Santo, Professora EBTT, Instituto Federal do Espírito Santo, tatianax@ifes.edu.br.

${ }^{3}$ Professora Doutora, coordenadora do Laboratório de Planejamento e Projetos da Universidade Federal do Espírito Santo, cristina.engel@ufes.br.
} 


\title{
THE INFLUENCE OF THE VEGETATION IN THE URBAN THERMAL COMFORT FOR CLIMATE CONDITION OF VITORIA (ES)
}

\begin{abstract}
The accelerated urban growth and the disorderly occupation of the ground may negatively influence the microclimate. Vegetation is an important instrument in the provision of an environment thermally more pleasant. The goal of this paper was to evaluate the impact of some different kinds of distribution of vegetation inserted in the urban environment related to the thermal comfort. It was considered an urban stretch that is typologically similar in the city of Vitoria (ES), located in the neighborhoods Jardim da Penha and Mata da Praia. For the measurements, four sampling points rectilinearly distributed from Pedra da Cebola Park were selected. The climatic variables temperature, humidity and wind speed were measured simultaneously for three hours uninterrupted in the summer, considering the most sunlight hours in the day. The data found in the measurements allows one to realize the influence of the vegetation as a strong constraint for the thermal comfort. It was found that the thermal influence of the vegetation concentrated in the park occurs only in the immediate surroundings regarding the temperature. However, regarding humidity, the interference radius is larger. The distributed vegetation shows more satisfactory results regarding temperature, when compared to its concentrated disposition, allowing one to conclude that, although the urban parks have influence in the comfort of the immediate surroundings, the distribution of vegetation in the urban environment tends to bring better results.
\end{abstract}

KEYWORDS: Urban vegetation. Urban climate. Thermal comfort.

\section{LA INFLUENCIA DE LA VEGETACIÓN EN EL CONFORT TÉRMICO URBANO PARA LA CONDICIÓN CLIMÁTICA DE VITÓRIA (ES)}

\begin{abstract}
RESUMEN
El rápido crecimiento urbano y el uso del suelo sin control pueden influir negativamente en el microclima y la vegetación es una importante herramienta en la ayuda para la obtención de un ambiente térmicamente más agradable. El objetivo de este estudio fue evaluar el impacto de los diferentes tipos de distribución de la vegetación insertadas en el entorno urbano con respeto al confort térmico. Fue considerado un tramo urbano, tipológicamente similar en la ciudad de Vitória (ES, Brazil), situado en los barrios Jardim da Penha y Mata da Praia. Para las mediciones, fueron seleccionados cuatro puntos de amuestra, distribuidos en línea desde el Parque Pedra da Cebola. Fueron medidas las variables climáticas temperatura, humedad y velocidad del viento, hechas simultáneamente durante tres horas ininterrumpidas en el verano, teniendo en cuenta los horarios de mayor incidencia solar del día. Los datos obtenidos en las mediciones permitieron comprobar la influencia de la vegetación como un fuerte elemento para el confort térmico. Se comprobó que la influencia térmica de la vegetación concentrada del Parque se produce sólo en el entorno inmediato con respecto a la temperatura, sin embargo, con respecto a la humedad, el radio de interferencia es más grande. La vegetación, cuando distribuida, resulta más satisfactoria en relación a la temperatura, en comparación a su disposición concentrada, concluyendo que, aunque los parques urbanos ejercen influencia en la comodidad de sus alrededores inmediatos, la distribución de la vegetación en el área urbana tiende a traer mejores resultado.
\end{abstract}

PALABRAS CLAVE: Vegetación urbana. Clima urbano. Confort térmico. 


\section{INTRODUÇÃO}

Devido à intensa urbanização e o crescimento populacional, a vegetação em áreas urbanas vem sendo reduzida, fazendo com que as cidades e suas intensas atividades antrópicas se tornem as grandes responsáveis pelas modificações climáticas locais, especialmente devido à intensificação do uso e ocupação do solo. Nos últimos anos tem aumentado o interesse em analisar o conforto térmico em espaços abertos visando à melhoria térmica de espaços existentes e o planejamento de novos espaços (NIKOLOPOULOU et al. 2006).

Garland (2010) destaca que os estudos realizados ao longo do século XX obtiveram como resultado a constatação de um aumento na temperatura em superfícies urbanas bastante superiores às verificadas em superfícies rurais. Nesse sentido, observa-se que no microclima urbano, a vegetação é um fator de grande importância, modificando a temperatura e umidade do ar principalmente em locais de clima tropical, sendo um condicionante para alterar a direção e velocidade do vento contribuindo para amenizar o rigor térmico do período sazonal quente (MASCARÓ; MASCARÓ, 2005).

Conforme afirmam Abreu (2008) e Labaki e outros (2011), apesar de já se saber que o efeito causado pela evapotranspiração da vegetação colabore na mitigação da radiação solar e da temperatura, por exemplo, pouco se conhece sobre a mensuração desses benefícios. Pode-se afirmar que o entendimento desses valores é fundamental para uma consciente utilização da vegetação no planejamento urbano, especialmente no que diz respeito à alteração das variáveis climáticas.

Diante do exposto, o objetivo desta pesquisa foi avaliar os benefícios resultantes da utilização de alguns tipos de inserção de vegetação no meio urbano no que diz respeito ao conforto térmico. Para a avaliação do impacto da vegetação no conforto térmico do entorno urbano foi selecionada a cidade (cidade e município não são sinônimos) de Vitória (ES), principalmente por suas características climáticas, sendo delimitado como recorte territorial um parque urbano denominado 
Parque Pedra da Cebola e áreas adjacentes do bairro Jardim da Penha e Mata da Praia.

\section{VEGETAÇÃO E CONFORTO TÉRMICO}

Os aspectos sociais relacionados à melhoria da qualidade de vida e do ambiente se tornaram evidentes quando os problemas ambientais decorrentes do desenvolvimento do sistema de produção, juntamente com a intensificação da urbanização e de questões ambientais se tornaram notórios, sendo pauta de preocupações nos anos 1960 e 1970 dos movimentos socioambientais, ocorrendo transformações nas formas de abordagem da climatologia brasileira e maior participação de pesquisadores nessa problemática (MENDONÇA; DANNIOLIVEIRA, 2007).

Nos estudos acerca do clima urbano, um dos aspectos que tem sido abordado é a relação das configurações urbanas com a formação de microclimas. Segundo Lima Neto (2011), a presença de vegetação nas cidades é essencial na estrutura e dinâmica da ambiência urbana, além de contribuir para atenuação da temperatura, proporcionando melhoria no conforto térmico dos transeuntes de cidades com temperaturas elevadas.

Segundo Abreu (2008) a falta de vegetação, entre outros aspectos, é um dos fatores responsáveis pelas alterações do clima urbano. A vegetação em áreas urbanas é um importante componente no microclima, contribuindo para o aumento da umidade relativa do ar, para a diminuição da temperatura e, consequentemente, para a melhoria do conforto térmico em ambientes tropicais. Dentre os benefícios da vegetação associada ao desenho urbano, Dacanal et all (2010), nos estudos sobre o papel dos fragmentos florestais urbanos no conforto térmico na cidade de CampinasSP, concluíram que a vegetação foi um fator relevante para o conforto térmico, sendo capaz de mitigar a temperatura do ar.

Há uma concordância no meio acadêmico de que a vegetação desempenha um papel fundamental nos fenômenos relacionados ao microclima urbano, sendo um 
fator importante para a diminuição da temperatura e como forma de mitigação de fenômenos de ilhas de calor. Entende-se por "ilha de calor" nos centros urbanos como o aumento significativo da temperatura, queda da umidade relativa do ar, variações na velocidade do vento e variabilidades das precipitações pluviométricas (MINAKI e AMORIM, 2012). Conforme Gartland (2010, p. 09) "o fenômeno ilhas de calor são formadas em áreas urbanas e suburbanas porque muitos materiais de construção comuns absorvem e retêm mais calor do sol do que materiais naturais em áreas rurais menos urbanizadas". Assim, as áreas com vegetação consistem em um 'oásis inverso', onde o ar e as temperaturas da superfície são mais quentes do que em áreas rurais circundantes (GARTLAND, 2010).

A vegetação geralmente, por ter uma baixa capacidade calorífica e condutibilidade térmica; bloquear parcialmente a radiação solar, absorvendo parte dessa radiação pelas folhas e refletindo muito pouco o restante; aumentar a taxa de evaporação; e permitir a permeabilidade do vento, contudo reduzindo sua velocidade, possibilita alterar as variáveis climáticas tornando o microclima mais ameno (ROMERO, 2007).

Segundo Abreu (2008), a influência da vegetação não se resume ao ambiente urbano, visto que ela também se propaga às edificações, podendo melhorar o conforto térmico interno e, consequentemente, possibilitando inclusive a redução dos gastos energéticos dispensados com condicionadores de ar.

\section{METODOLOGIA}

Para execução desta pesquisa, a metodologia utilizada foi dividida em seis etapas, sequenciais e/ou concomitantes, sendo elas: revisão bibliográfica, delimitação da área de estudo, escolha dos pontos de amostragem climática, preparação dos equipamentos de medição, levantamento de dados e análise dos resultados (Figura. 1). 
Figura 1: Fluxograma dos procedimentos metodológicos

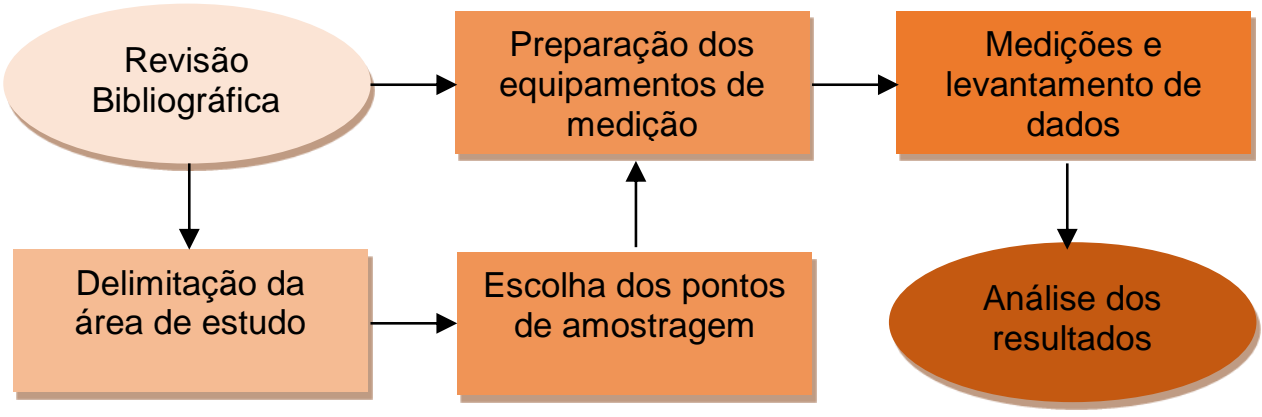

Fonte: AUTORES, 2015.

A revisão bibliográfica permeou todo o processo da pesquisa, balizando teoricamente no que diz respeito ao clima urbano, conforto térmico, influência da vegetação em relação às variáveis climáticas estudadas, medições microclimáticas e demais questões intrínsecas ao assunto. Nessa etapa também foram realizados os levantamentos documentais, tais como mapas, plantas georreferenciadas da cidade, imagens aéreas, entre outros.

Considerando o objetivo da pesquisa, o recorte territorial foi estabelecido a partir dos seguintes critérios: ser uma área urbana de Vitória (ES); características tipológicas semelhantes, especialmente relacionadas à ocupação no lote, altura das edificações e gabarito das vias; área com significativa concentração de vegetação (para identificação da área de influência), bem como com exemplos de vegetação distribuídas pontualmente e sequencialmente. Para isso, elegeu-se o Parque Pedra da Cebola e suas imediações, abrangendo os bairros Mata da Praia e Jardim da Penha. A cidade, segundo a escala Koppen, possui clima tropical úmido ( $A w)$ e está localizada na LAT 20 19' 20" S e LONG 40 20' 17" W (IBGE - Cidades 2014).

O Parque Municipal Pedra da Cebola, inaugurado em 1997, localiza-se no bairro Mata da Praia e comporta vegetação de Mata de Restinga e de Mata Atlântica, além de vegetação rupestre nativa, dentro dos mais de 100 mil metros quadrados de área que possui, e é o primeiro monumento natural de recuperação de área degradada por atividade econômica de extração de rochas no município (SECRETARIA DE MEIO AMBIENTE DE VITÓRIA, 2014).

A partir da área delimitada, foram eleitos quatro pontos para a realização das medições microclimáticas simultâneas das variáveis temperatura, umidade e 


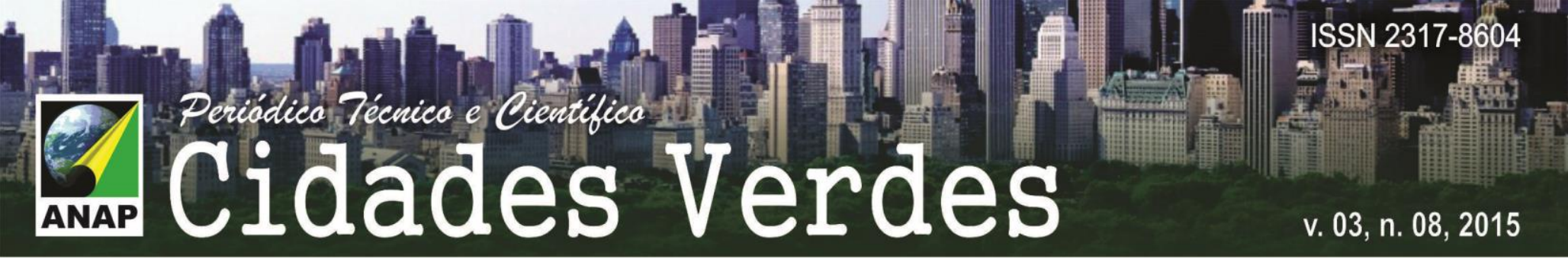

Figura 3: À esquerda, croqui e à direita, imagem do ponto 1, localizado nas coordenadas: LAT. 20¹6'37.18"S - LONG. 40¹7'55.88" W - Altitude: +/- 3 m
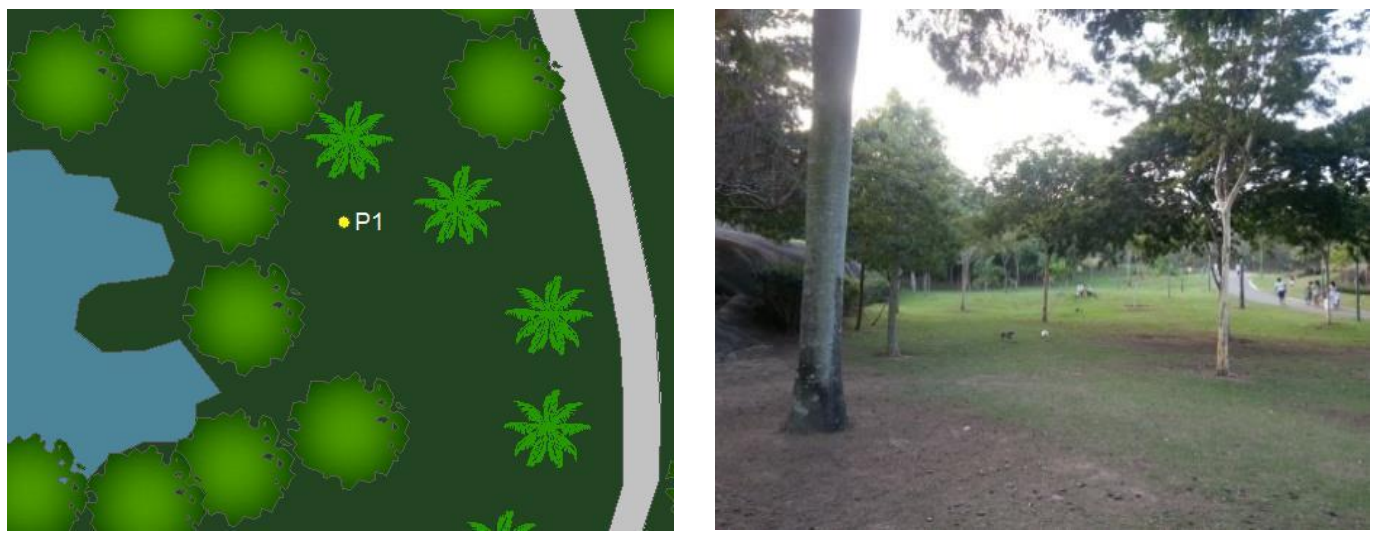

Fonte: AUTORES, 2015.

O ponto 2 localiza-se no bairro Mata da Praia, nas imediações do Parque Pedra da Cebola, possuindo poucos exemplares de vegetação de grande porte distribuída em pequenas áreas, sendo que a região é cercada por edificações, conforme mostra a figura 4.

Figura 4: À esquerda, croqui e à direita, imagem do ponto 2, localizado nas coordenadas: LAT. $20^{\circ} 16^{\prime} 42.25 " \mathrm{~S}$ - LONG.: 40¹7'56.68" W - Altitude: +/- $3 \mathrm{~m}$
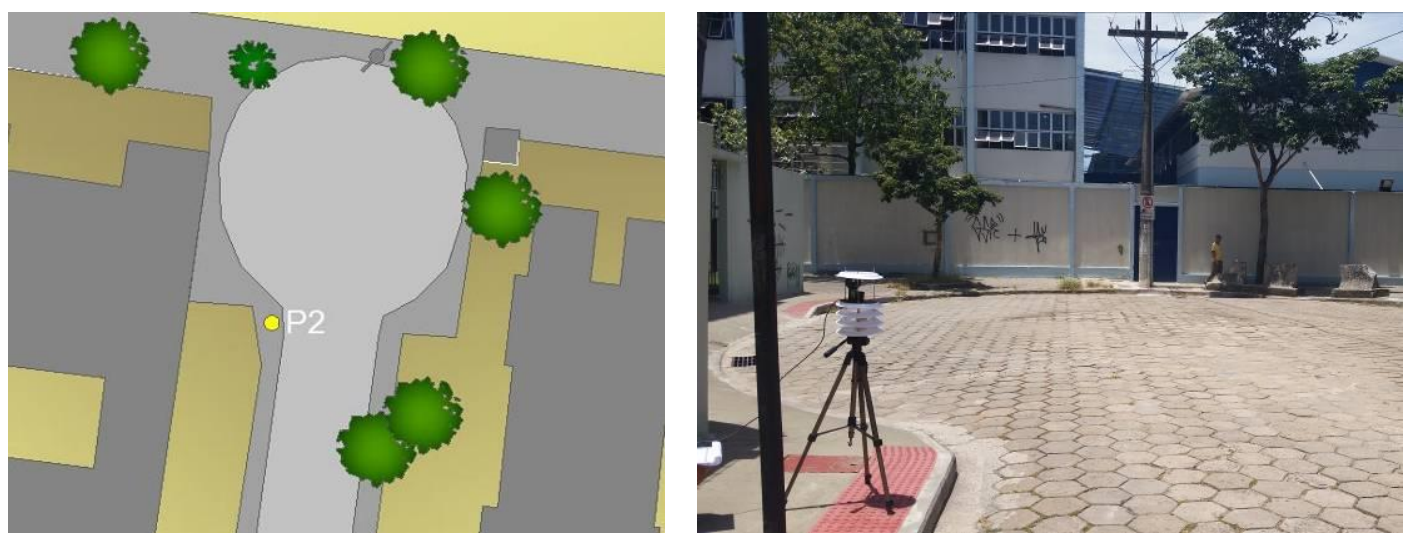

Fonte: AUTORES, 2015.

Também no bairro Mata da Praia, o ponto 3 localiza-se em uma área com edificações ao seu redor e possui concentração de vegetação de grande porte no canteiro central da rua transversal que fica ao lado, como pode ser observado na figura 5. 


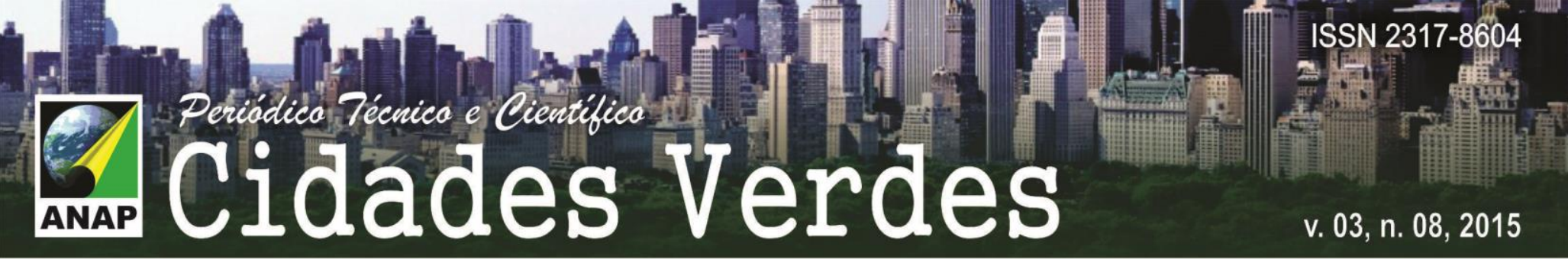

Figura 5: À esquerda, croqui e à direita, imagem do ponto 1, localizado nas coordenadas: LAT. $20^{\circ} 16^{\prime} 46.11 " \mathrm{~S}$ - LONG.: 40¹7'57.41" W - Altitude: +/- $3 \mathrm{~m}$
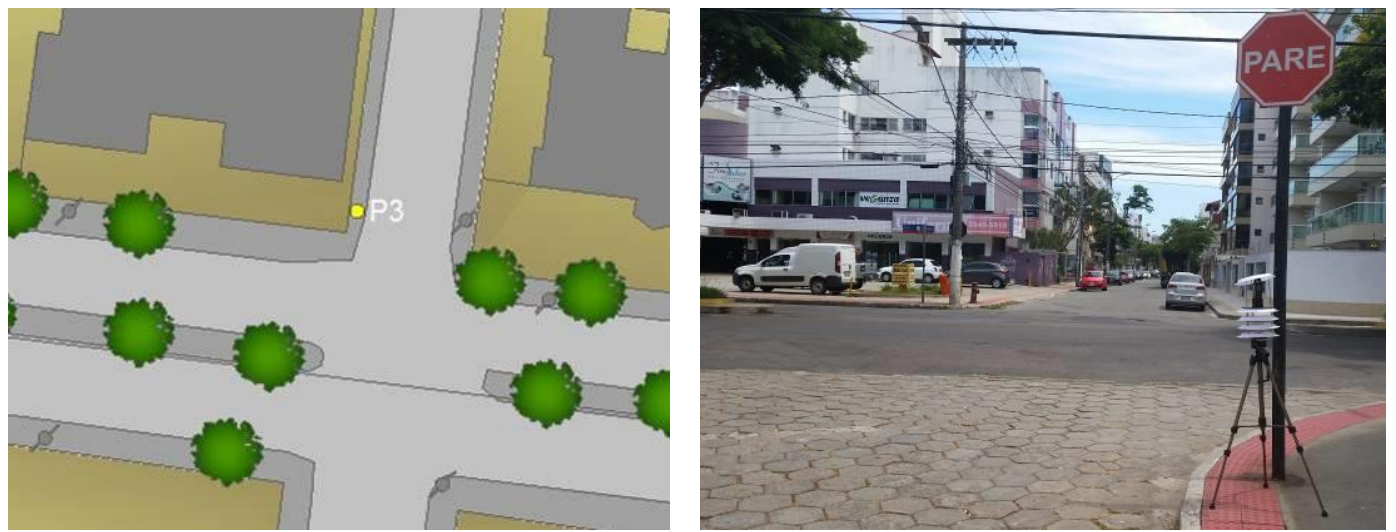

Fonte: AUTORES, 2015.

O ponto 4 localiza-se no bairro Jardim da Penha, também é cercado por edificações e possui concentração de vegetação de grande porte no canteiro central da rua transversal, conforme mostra a figura 6.

Figura 6: À esquerda, croqui e à direita, imagem do ponto 1, localizado nas coordenadas: LAT. 20¹6'49.52"S - LONG.: 40¹7'58.33" W - Altitude: +/- 3 m
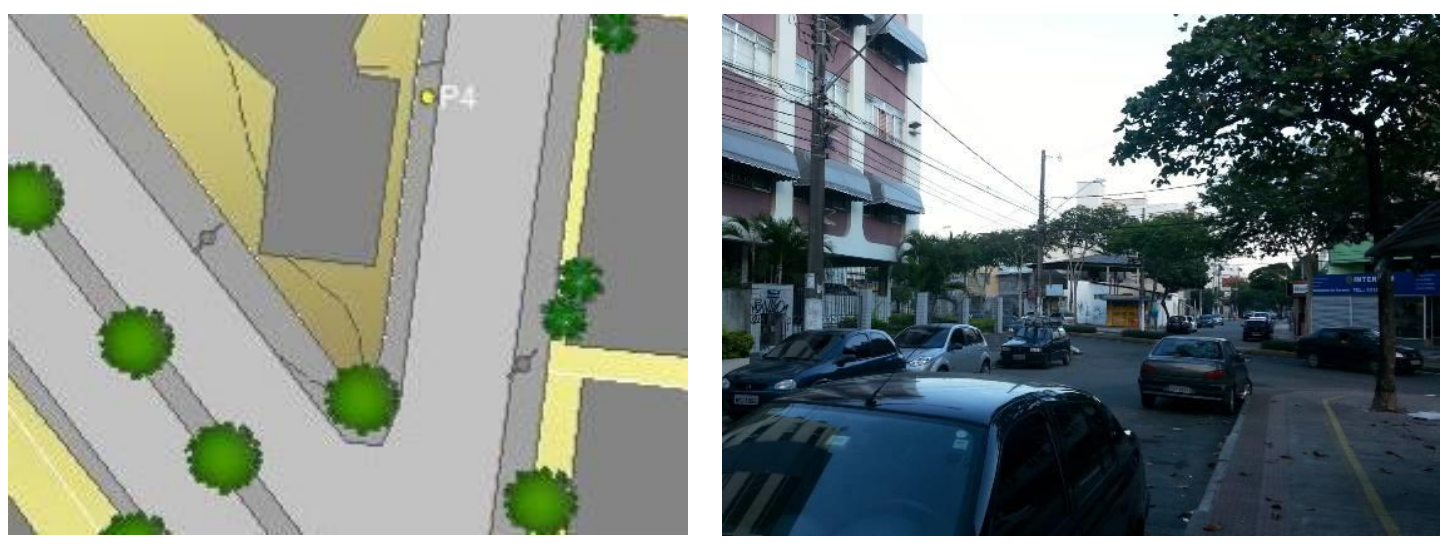

Fonte: AUTORES, 2015.

As variáveis climáticas foram registradas por meio de equipamentos fixados em abrigos dispostos em cada ponto de amostragem. Os equipamentos utilizados foram quatro Termo-Higro-Anenômetros, modelo INSTRUTEMP (ITAN 700) e quatro Data Loggers, modelo ONSET HOBO (Temp/RH/ 2 extchannels), posicionados a $110 \mathrm{~cm}$ do solo (altura do abdômen), de acordo com a ISO 7726 (1998). Para cada 
ponto foi confeccionado uma miniestação composta de um termo-higro-anemômetro, um Data Logger, um tripé e um abrigo. Os aparelhos foram alocados sobre um tripé e protegidos da radiação solar direta por meio de um abrigo meteorológico confeccionado com pratos de poliestireno expandido (Figura 7).

Figura 7: Miniestação. À esquerda, detalhe do abrigo.
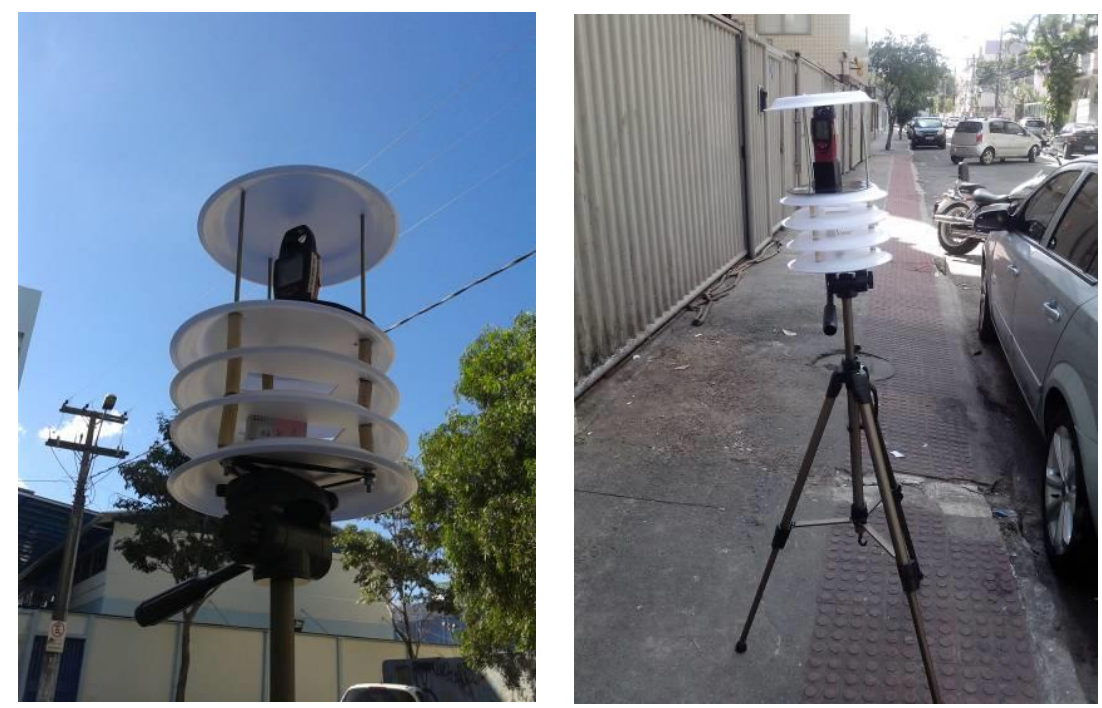

Fonte: AUTORES, 2015

As medições ocorreram no dia 14 de janeiro de 2015 no período entre $12 \mathrm{~h}$ e $15 \mathrm{~h}$, considerando o horário de maior incidência solar, o que ofereceria a situação mais crítica termicamente, conforme previamente definido na metodologia. A condição do céu era claro com poucas nuvens.

Os dados de velocidade do vento, temperatura e umidade foram medidos durante o período, sendo registrados os dados microclimáticos de cada ponto de amostragem. Para os registros de velocidade do vento foram utilizados os TermoHigro-Anenômetros, obtidos em intervalos de 15 em 15 minutos, registrando-se os valores de máxima, mínima e média para cada ponto. Os valores de temperatura e umidade foram registrados a cada minuto nos Data Loggers e posteriormente extraídos no computador.

Para análise dos resultados, os dados foram sistematizados (tabulados), sendo confeccionados gráficos dos valores registrados em cada ponto, visando 
facilitar a comparação e análise das informações obtidas nas medições microclimáticas.

\section{ANÁLISE DOS DADOS}

O ponto 1, que está localizado no parque Pedra da Cebola, possui na maior parte do tempo os valores mais baixos de temperatura e mais altos de umidade em relação aos demais, o que se justifica pela concentração de vegetação, comprovando sua aplicabilidade satisfatória na obtenção de um ambiente climaticamente mais agradável (Figura 8).

Figura 8: Gráfico com os dados de temperatura e umidade dos 4 pontos de medição

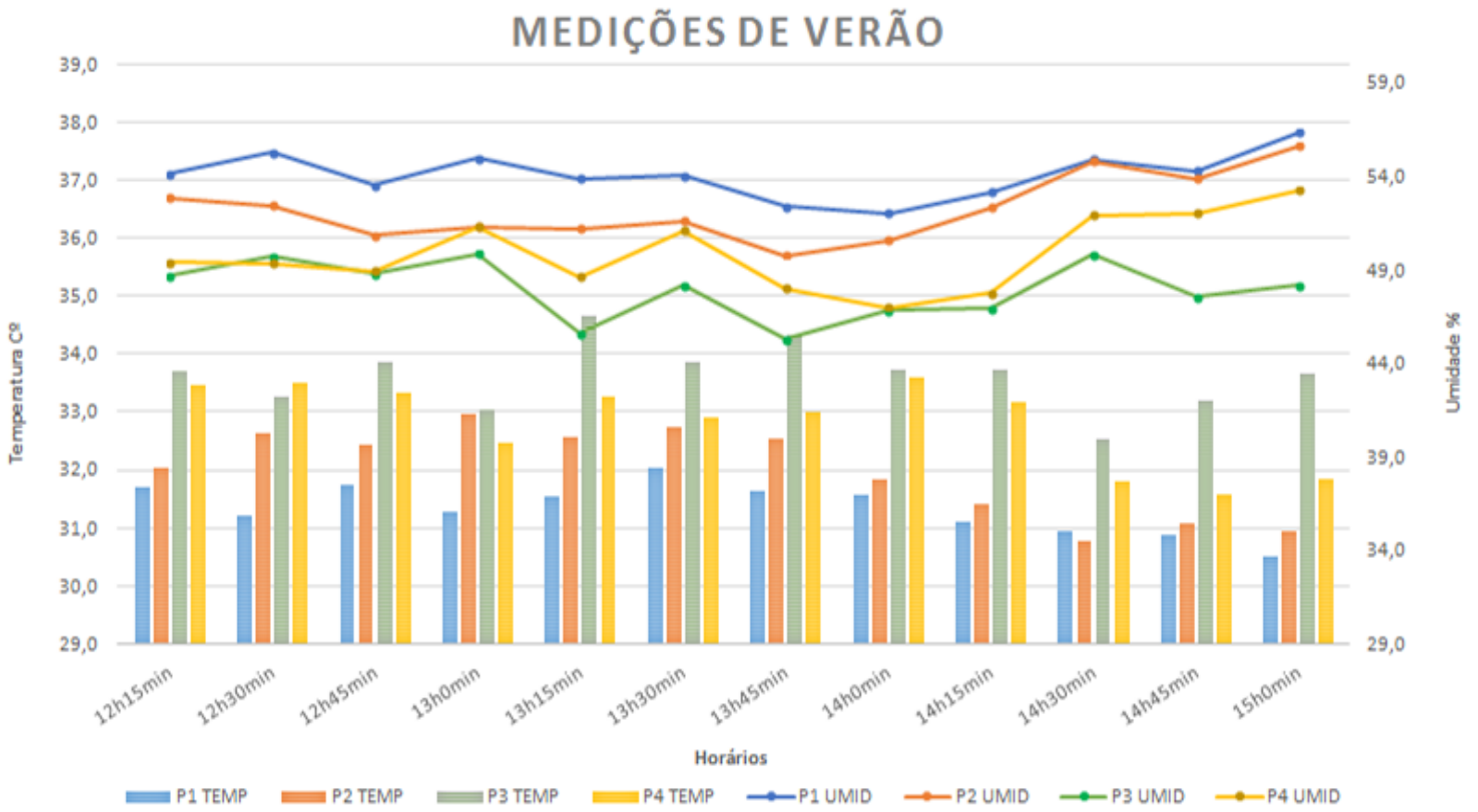

Fonte: AUTORES, 2015.

A velocidade do vento no ponto 1 foi a segunda mais alta, observando-se que, apesar de possuir vegetação concentrada, é uma área aberta, com espaçamento entre a vegetação, o que permite a permeabilidade do vento (Tabela 1). 


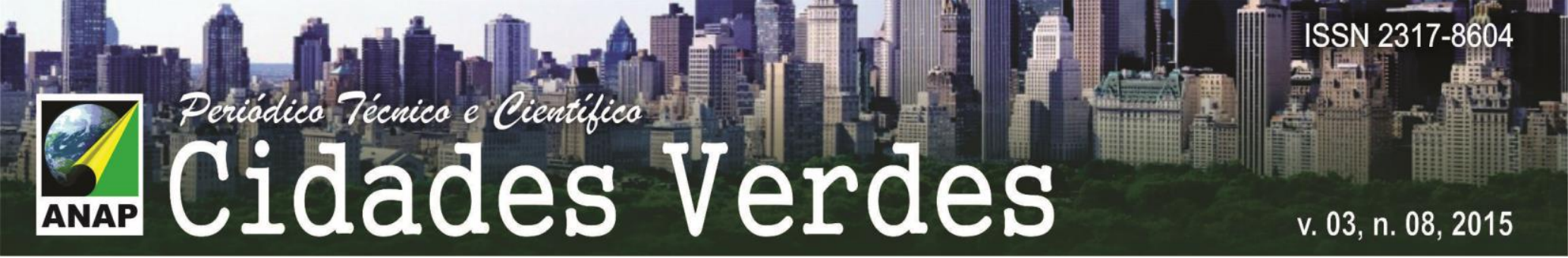

ainda, que a superfície do ponto é atingida pela radiação e aquecida desde aproximadamente $5 \mathrm{~h} 30$, conforme máscara produzida com a carta solar de Vitória.

Figura 9: Máscara solar referente ao ponto 3

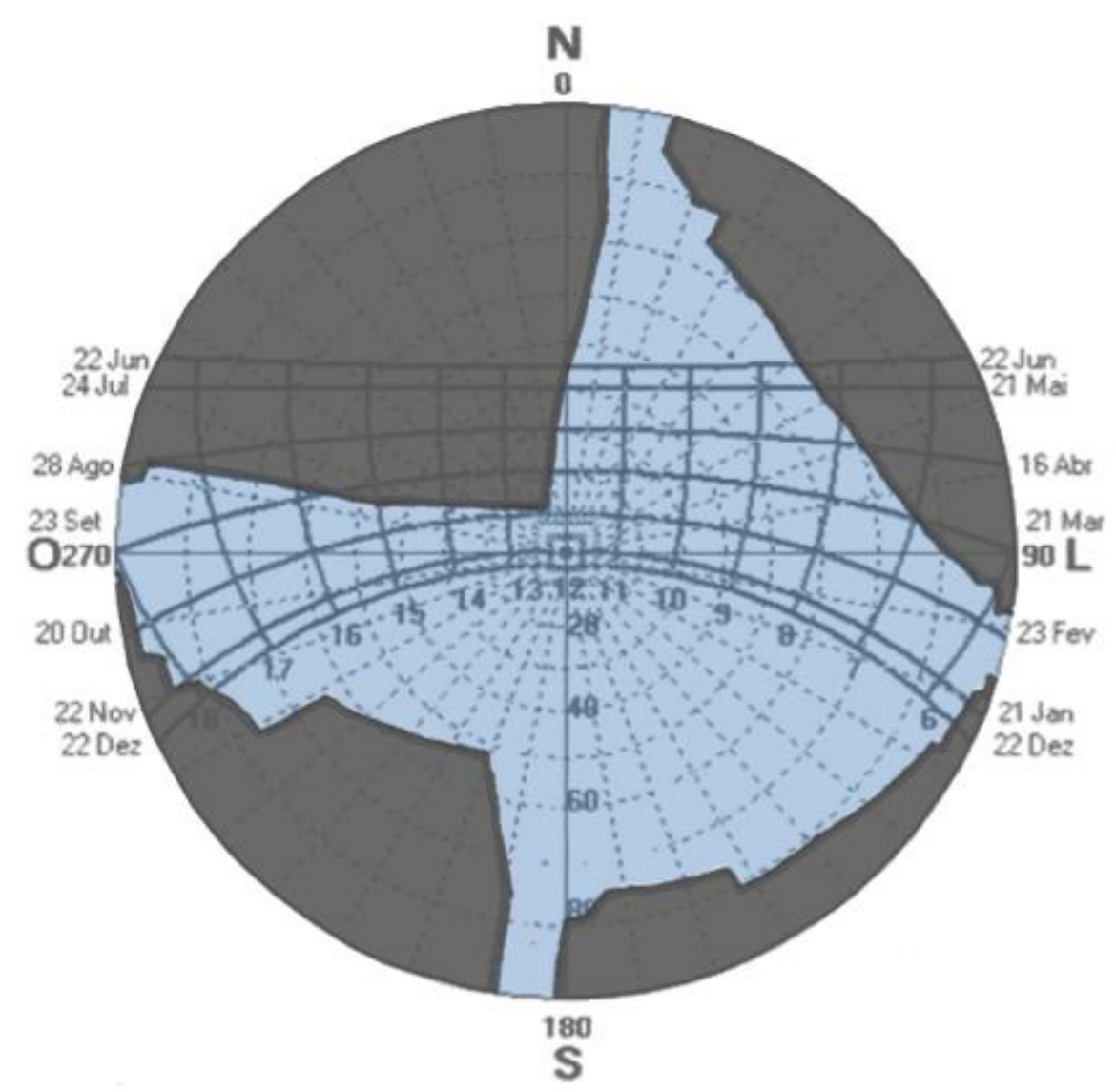

Fonte: Modificado a partir da base extraída do programa SOL-AR, 2015.

\section{CONCLUSÃO}

A partir da avaliação e comparação dos dados obtidos nas medições microclimáticas foi possível perceber a influência dos diferentes tipos de distribuição de vegetação no conforto térmico dos transeuntes no ambiente ao qual se encontra inserido, assim como a interferência de outros aspectos, como, por exemplo, a tipologia urbana. 
Nos espaços onde a concentração de vegetação é maior, a temperatura permanece mais amena ao longo do dia, enquanto a umidade atinge valores mais altos. Foi possível verificar que a vegetação concentrada interfere no microclima do entorno imediato, porém seu raio de influência é limitado. Desse modo, o ponto 2 , que é o que possui menos vegetação mas por se encontrar próximo ao parque, apresenta temperatura e umidade mais agradáveis do que os pontos 3 e 4 que são mais vegetados que este.

A vegetação concentrada do parque chega a diminuir a temperatura, em média, em cerca de $1^{\circ} \mathrm{C}$ em relação aos outros pontos, atingindo a diferença de $3^{\circ} \mathrm{C}$ às $13 \mathrm{~h} 15 \mathrm{e}$ às $15 \mathrm{~h}$ em comparação com o ponto 3 .

No ponto 4 a vegetação se encontra de maneira distribuída e também apresenta valores expressivos em relação à queda na temperatura, demonstrando que a vegetação distribuída na cidade, nas calçadas e canteiros centrais também apresentam forte contribuição para um microclima mais ameno.

Os dados encontrados permitiram verificar que cada tipo de inserção da vegetação no meio urbano terá sua contribuição de forma diversa em relação ao conforto térmico. Portanto, é necessário avaliar a melhor forma de implantação da vegetação de acordo com o desenho urbano e o conforto térmico pretendidos.

Cabe ressaltar que esta avaliação foi feita em uma parcela da cidade litorânea de Vitória (ES), podendo ser reproduzida em locais com clima e características similares, porém não sendo estes dados passíveis de generalização para qualquer área urbana.

\section{AGRADECIMENTOS}

À Rede Urbenere, financiada pelo CYTED, que apoia a pesquisa; ao Programa de Pós Graduação em Arquitetura e Urbanismo da Ufes e à FACITEC, pelo apoio na forma de bolsa. 


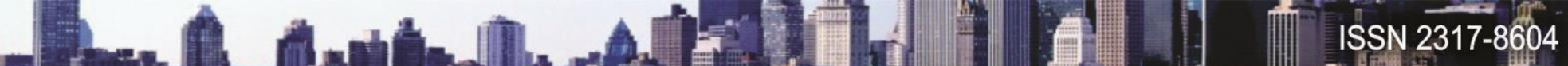

\section{REFERÊNCIAS}

ABREU, L. V. 2008. Avaliação da escala de influência da vegetação no microclima por diferentes espécies arbóreas. $154 \mathrm{f}$. Dissertação (Mestrado em Engenharia Civil) - Faculdade de Engenharia Civil, Universidade Estadual de Campinas, Campinas.

DACANAL, C.; LABAKI, L.C.; SILVA, T. M. L. Vamos passear na floresta! O conforto térmico em fragmentos florestais urbanos. Ambiente Construído, Porto Alegre, v. 10, n. 2, p. 115-132, abr./jun. 2010.

GARTLAND, L. Ilhas de calor: como mitigar zonas de calor em áreas urbanas. Tradução: Sílvia Helena Gonçalves. São Paulo: Oficina de Textos, 2010. 248 p.

GOOGLE. Software Google Earth 7. Estados Unidos, 2013. Disponível em: < http://www.google.pt/earth/>. Acesso em 20 mai. 2015.

INTERNATIONAL ORGANIZATION FOR STANDARDIZATION. ISO 7726 - Ergonomics of the termal environment: Instruments for measuring physical quantities. 1998.

INSTITUTO BRASILEIRO DE GEOGRAFIA E ESTATÍSTICA. IBGE - Cidades, 2014. Disponível em <http://cidades.ibge.gov.br/xtras/perfil.php?lang=\&codmun=320530 >. Acesso em 20 mai. 2015.

KOTTEK, M.; GRIESER, J.; BECK, C.; RUDOLF, B.; RUBEL, F. World Map of the Koppen-Geiger climate classification updated. Meteorol Zeitschrift 15 (3): 259-26, 2006.

LABAKI, L. C.; SANTOS, R. F. S.; BUENO-BARTHOLOMEI, C. L.; ABREU, L. V. A. Vegetação e conforto térmico em espaços urbanos abertos. Fórum Patrimônio, Belo Horizonte, 2011.

LABORATÓRIO DE EFICIÊNCIA ENERGÉTICA EM EDIFICAÇÕES. Software Analysis SOL-AR. Versão 6.2. Disponível em < http://www.labeee.ufsc.br/downloads/softwares>. Acesso em 15 mai. 2015.

LIMA NETO, E. M. Aplicação do sistema de informações geográficas para o inventário da arborização de ruas de Curitiba, PR. 120 f. Dissertação (Mestrado em Engenharia Florestal) - Setor de Ciências Agrárias, Universidade Federal do Paraná, Curitiba, 2011.

MASCARÓ, L; MASCARÓ J. Vegetação Urbana. 2ed. Porto Alegre: Editora +4, 2005. 204 p.

MENDONÇA, F.; DANNI-OLIVEIRA, I. M. Climatologia: noções básicas e climas do Brasil. São Paulo: Oficina de Textos, 2007.

MINAKI C.; AMORIM, M. C. de C. T. 2012. Características das ilhas de calor em Araçatuba/SP: Análise de episódios. Revista Geonorte, ISSN: 2237-1419, Edição Especial 2, V.2, N.5, p. 279 - 294.

NIKOLOPOULOU, M.; KRUGER, E.; ROSSI, F. A. A Influência da configuração urbana no microclima e na sensação térmica em ruas de pedestre de Curitiba, Paraná. ENCONTRO NACIONAL DE CONFORTO CONSTRUÍDO. Búzios. Rio de Janeiro, 2011.

ROMERO, M. A. B. Arquitetura bioclimática do espaço público. Brasília: Editora Universidade de Brasília, 2007.

SECRETARIA DE MEIO AMBIENTE DE VITÓRIA. Parque pedra da cebola. Disponível em: <http://www.vitoria.es.gov.br/semmam.php?pagina=pedradacebola>. Acesso em: 20 mai. 2015. 